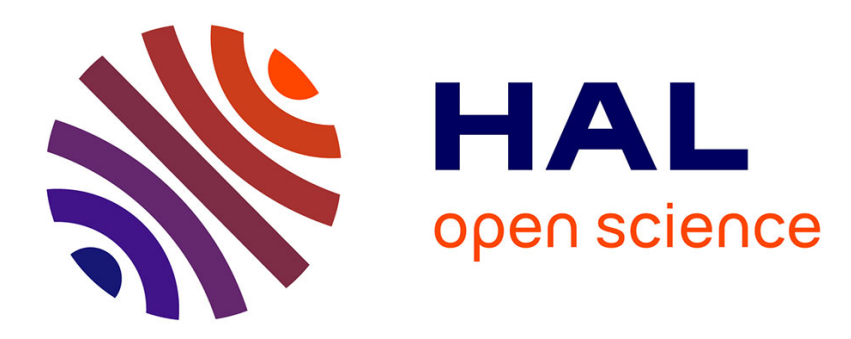

\title{
A Pedagogical Note on Risk Sharing Versus Instability in International Financial Integration: When Obstfeld Meets Stiglitz
}

\author{
Raouf Boucekkine, Benteng Zou
}

\section{- To cite this version:}

Raouf Boucekkine, Benteng Zou. A Pedagogical Note on Risk Sharing Versus Instability in International Financial Integration: When Obstfeld Meets Stiglitz. Open Economies Review, 2019, 30 (1), pp.179-190. 10.1007/s11079-018-9514-z . hal-01996294

\section{HAL Id: hal-01996294 \\ https://hal-amu.archives-ouvertes.fr/hal-01996294}

Submitted on 30 Apr 2020

HAL is a multi-disciplinary open access archive for the deposit and dissemination of scientific research documents, whether they are published or not. The documents may come from teaching and research institutions in France or abroad, or from public or private research centers.
L'archive ouverte pluridisciplinaire HAL, est destinée au dépôt et à la diffusion de documents scientifiques de niveau recherche, publiés ou non, émanant des établissements d'enseignement et de recherche français ou étrangers, des laboratoires publics ou privés. 


\title{
A Pedagogical Note on Risk Sharing Versus Instability in International Financial Integration: When Obstfeld Meets Stiglitz
}

\author{
Raouf Boucekkine ${ }^{1} \cdot$ Benteng Zou ${ }^{2}$
}

\begin{abstract}
The pure risk sharing mechanism implies that financial liberalization is growth enhancing for all countries as the world portfolio shifts from safe low-yield capital to riskier high-yield capital. This result is typically obtained under the assumption that the volatilities for risky assets prevailing under autarky are not altered after liberalization. We relax this assumption within a simple two-country model of intertemporal portfolio choices. By doing so, we put together the risk sharing effect and a welldefined instability effect. We identify the conditions under which liberalization may cause a drop in growth. These conditions combine the typical threshold conditions outlined in the literature, which concern the deep characteristics of the economies, and size conditions on the instability effect induced by liberalization.
\end{abstract}

Keywords Economic growth · Financial liberalization · Risk sharing · Volatility · Emerging markets

JEL Classification F21 - G15 · O16 · O41

This author appreciates the financial support from NSFC Project 71573230

$\triangle$ Raouf Boucekkine

Raouf.Boucekkine@univ-amu.fr

Benteng Zou

benteng.zou@uni.lu

1 Aix-Marseille University (IMéRA and AMSE), and senior member of the Institut Universitaire de France, 2, Place Le Verrier, 13004, Marseille, France

2 CREA, University of Luxembourg, 162a, avenue de la Faiencerie, L-1511, Luxembourg City, Luxembourg 


\section{Introduction}

The growth impact of financial liberalization is still at the heart of many ongoing research programs. While the arguments in favor of international financial integration are pretty clear (essentially, access to larger savings and international risk sharing), the findings of the related empirical studies are much more ambiguous. Indeed, a common view in the literature is that financial liberalization may be beneficial or not depending on whether the countries' fundamentals are above certain threshold levels (see for example Kose et al. 2011). In particular, it is nowadays broadly argued that financial and institutional development, in particular the soundness of the national financial systems, should be above a certain level in order to reduce the risks associated with financial openness.

In an important review paper, Stiglitz (2000) took a remarkable stance against the potential inconveniences of financial liberalization, going well beyond the "threshold" literature mentioned just above. In particular, Stiglitz wrote: “...As the crisis spread from East Asia to Russia, and then to Latin America, it became clear that even countries with good economic policies and relatively sound financial institutions...were adversely affected, and seriously so. Indeed, this was consistent with earlier research that had shown that changes in capital flows, and even crises, were predominantly precipitated by events outside the country...in the more developed countries" (page 1075). That's to say, even if, in the spirit of Kose et al., the threshold conditions for a beneficial financial liberalization are met, the scope for potential instability is so big that the intended advantages (access to larger savings, risk sharing) can be offset.

A perfect illustration of Stiglitz's claim is the case of emerging economies. Intuitively, capital inflow to emerging markets should lower the cost of capital (Bekaert and Harvey 2000) and thus stimulates economic growth in these economies (Bekaert et al. 2005, 2006; Moshirian 2008; Levine 2001). At the same time, there are also evidence showing that the effect from financial market liberalization is unclear or mixed (Prasad et al. 2003; Eichengreen 2001). Arguably, the opposite views lie on different concerns. One of these concerns is that financial market liberalization may increase the volatility of emerging markets (Bae et al. 2004; Umutlu et al. 2010, or Harvey 1995) and volatility is negatively related to economic growth (Ramey and Ramey 1995). The latter argument is at the heart of Stiglitz stance for the regulation of (notably short-term) capital flows.

This paper is essentially a pedagogical contribution to this debate. In a seminal contribution, Obstfeld (1994) explored the pure international risk sharing mechanism and its impact on growth. The main conclusion of Obstfeld is that under quite mild conditions, ${ }^{1}$ opening the asset markets to trade causes the expected growth rate to rise in all countries thanks to the world portfolio shift from safe low-yield capital to riskier high yield capital. The empirical studies showing negative correlation between

\footnotetext{
${ }^{1}$ See page 1311, left column, first paragraph: “...Provided risky returns are imperfectly correlated across countries, and provided some risk free assets are initially held, a small rise in diversification opportunities always raises exected growth as well as national welfare".
} 
financial liberalization and growth cannot be opposed to Obstfeld's conclusion because it is only concerned with the pure international risk sharing and deliberately disregards the many other mechanisms that can matter. In particular, Obstfeld draws his conclusions based on the explicit assumption that liberalization does not change the volatility of the risky assets, that is the volatility figures prevailing under autarky are not altered after opening the asset markets.

In this note, we relax the latter assumption and allow these volatilities to change as a result of financial liberalization. We also place ourselves under the mild assumptions ensuring that pure risk sharing mechanism inherent in international financial integration is growth and welfare-enhancing in the Obstfeld model. By proceeding so, we shall extend Obstfeld's analysis to allow for the instability argument highlighted by Stiglitz. Needless to say, putting the pure risk sharing and instability mechanisms together will markedly enrich the analysis, which in turns permits to cope much more easily with the contrasted related empirical literature. Three remarks are worth doing here. First of all, we could have indeed taken an agnostic view of how financial liberalization alters the volatilities of risky assets, which would have significantly increased the set of possible outcomes. To unburden the presentation and to make it focused enough, we concentrate on the emerging economies case for which, as mentioned above, there is compelling evidence that liberalization has indeed raised volatility in several cases. Second, we do not endogenize the volatility variations induced by liberalization, and only consider exogenous changes in these figures. Of course, there are several mechanisms and events which can cause such variations, some may be indeed exogenous due to contagion as outlined by Stiglitz (see above) and others may derive from the countries' deep characteristics in line with threshold literature pushed by Kose and his co-authors. Boucekkine and Pintus (2012) and Boucekkine et al. (2018) have for example highlighted the role of external debts in driving macroeconomic and financial instability. More recently, Kitano and Takaku (2017) outline the role of financial frictions in fostering macroeconomic and financial volatility of the emerging countries. They end up advocating for appropriate capital controls for such countries. Third, in the spirit of Obstfeld's model, we do not distinguish between FDI's and short-term capital flows. Stiglitz's argument refers essentially to the latter. We could have made our model more specific to cope with this difference but we believe that the use of a simple version of a generic model like Obstfeld's serves better the objectives of this note.

The rest of paper is organized as follows. We restate the closed and open economy of Obstfeld (1994) in Sections 2 and 3. In particular, the long-run average growth rates are obtained in both cases. In Section 4, we study in detail the case of emerging economies. Section 5 concludes.

\section{Autarkic Economy}

Suppose that in one closed economy, all individuals are identical and live forever. At each moment in time, individuals face the choice between consumption and investment. Suppose furthermore, the utility of each individual is $U\left(c_{t}\right)=\frac{c_{t}^{1-\gamma}}{1-\gamma}$ where $c_{t}$ 
reads time t consumption for $\gamma>0$ with $U\left(c_{t}\right)=\operatorname{Ln}\left(c_{t}\right)$ when $\gamma=1$ as usual. Note that Obstfeld's analysis builds on a larger set of preferences, namely recursive preferences. Here, we consider the standard intertemporal additively-separable welfare function with CARA instantaneous utility. $\gamma$ represents relative-risk aversion parameter and $\frac{1}{\gamma}$ is intertemporal substitution elasticity. This special case is enough to build our argument with minimal algebra.

Each individual has initial wealth $W_{0}$ as endowment, which can be consumed or invested. Thus, per capital wealth holding is $W_{t}=B_{t}+K_{t}$. Here, $B_{t}$ is per capita risk free asset holding whose dynamics are: $d B_{t}=r B_{t} d t$ with $r$ the return from risk free asset, assumed to be a fixed constant. $K_{t}$ is the per capita risky asset holding given by the stochastic law of motion: $d K_{t}=\alpha K_{t} d t+\sigma K_{t} d z_{t}$, where $z=\left(z_{t}\right)_{t \geq 0}$ is a standard Wiener process, $\alpha$ is the risky asset drift and $\sigma$ is the risky asset volatility, respectively. For simplicity, we assume both are fixed constants. For the optimal portfolio choice problem to make sense, we assume as usual that the risky asset has a larger expected return: $\alpha>r$. Following (Obstfeld 1994), we assume also that there is no nondiversifiable income (such as labor income), thus the asset markets in this autarkic economy are complete.

Combining the above two dynamic processes together yields the dynamics of wealth: $d W_{t}=\left(r B_{t}+\alpha K_{t}-c_{t}\right) d t+\sigma K_{t} d z_{t}$. Denote by $\omega_{t}=\frac{K_{t}}{W_{t}}$ the share of risky assets in total wealth holding, then $\frac{B_{t}}{W_{t}}=1-\omega_{t}$. The law of motion of wealth is:

$$
d W_{t}=\left(r W_{t}+(\alpha-r) W_{t} \omega_{t}-c_{t}\right) d t+\sigma W_{t} \omega_{t} d z_{t} .
$$

Therefore, this economy's optimization problem is:

$$
\max _{c_{t}, \omega_{t}} \mathbb{E} \int_{0}^{\infty} e^{-\rho t} U\left(c_{t}\right) d t=\mathbb{E} \int_{0}^{\infty} e^{-\rho t} \frac{c_{t}^{1-\gamma}}{1-\gamma} d t,
$$

where parameter $\rho(>0)$ is time preference and $\mathbb{E}$ is mathematical expectation, subject to the budget constraint (1).

Denote by $v(W)$ the maximum feasible level of lifetime utility with wealth level at $W$. Then, following the standard lifetime portfolio choice process proposed by Merton (1971), we have

$$
c_{t}^{*}=\left[v_{0}(1-\gamma)\right]^{-\frac{1}{\gamma}} W_{t}^{*}, \quad \omega_{t}^{*} \equiv \frac{1}{\gamma} \frac{\alpha-r}{\sigma^{2}} .
$$

with

$$
v(W)=v_{0} W^{1-\gamma} \text { and } v_{0}=\frac{1}{1-\gamma}\left(\frac{\rho-r}{\gamma}-\frac{(1-\gamma)}{2 \gamma^{2}}(\alpha-r)^{2} \sigma^{2}\right)^{-\gamma} .
$$

From now on, we only assume interior solutions for the optimal portfolio choice problems. In the autarkic case, this means that we assume that the parameters of the problem assure that $0<\omega_{t}^{*}<1$. This is one of the two mild conditions posed by Obstfeld (1994) for the pure risk sharing mechanism to promote growth and welfare after opening: the economy must hold initially some risk-free assets. The second condition is imperfect correlation between risky returns across countries, we shall also assume it in the next section. 
Substituting the optimal choice into the equation of wealth accumulation, it yields

$$
\frac{d W_{t}}{W_{t}}=\mu d t+v d z_{t}
$$

where the constants $\mu$ and $v$ are defined as

$$
\mu:=r+\frac{(\alpha-r)^{2}}{\sigma^{2} \gamma}-\left[v_{0}(1+\gamma)\right]^{-1 / \gamma}, \quad v:=\frac{1}{\gamma} \frac{\alpha-r}{\sigma}
$$

Thus, the optimal wealth is $W_{t}^{*}=W_{0} \exp \left[\left(\mu-\frac{v^{2}}{2}\right) t+v z_{t}\right]$. Therefore, the growth rate of the almost sure trajectory is

$$
g_{a}:=\mu-v^{2} / 2=r-\frac{\rho-r}{\gamma}+\frac{1}{2 \gamma} \frac{(\alpha-r)^{2}}{\sigma^{2}}
$$

which is constant over the probability space.

Expression (2) and (3) imply that the share of risky assets in total wealth is decreasing in the risky asset's volatility $\left(\frac{\partial \omega_{t}^{*}}{\partial \sigma}<0\right)$, which in turns implies that the wealth volatility is also decreasing in the risky asset's volatility $\left(\frac{\partial \nu}{\partial \sigma}<0\right)$.

Rewrite (3) as $\gamma v=\frac{\alpha-r}{\sigma}$ and recall that $\gamma$ measures relative risk aversion. Thus, expression $\frac{\alpha-r}{\sigma}$ can be renamed as relative-risk-averse-wealth volatility. The above study can be concluded with the following important statement.

Proposition 1 Both the share of risky asset holding and the relative-risk-aversewealth volatility are decreasing in terms of the volatility of the risky asset.

In the next section, we shall open the economy to international asset trade. In particular, we shall move to a two-country framework. To single out the pure risk sharing effect, Obstfeld (1994) assumed that the volatilities of the risky assets (here $\sigma$ for the closed economy case) remain unchanged after liberalization. We shall depart from this assumption. Accordingly, we shall denote the volatility of risky assets before opening for each of the countries, say $i=1,2, \sigma_{i a}$, while these volatilities turn to $\sigma_{i o}$ after liberalization.

\section{Open Economy - the Two-Country Case}

Consider two countries which open their asset markets to each other with the same risk free asset yielding the same world interest rate, and two risky assets. Denote then by $W=\left(W_{t}^{i}\right)_{t \geq 0}$ the wealth process of country $i(\mathrm{i}=1,2), B_{t}^{i}$ being the amount of riskless asset held at time $t$ by country $i$, and $K_{t}^{i, j}$ being the amount of risky asset $j(\mathrm{j}=1,2)$ held by country $i$ at time $t$. We set $\mathbf{K}^{i}=\left(\begin{array}{l}K^{i, 1} \\ K^{i, 2}\end{array}\right)$, which now follows a stochastic differential equation in a two-dimensional space. Furthermore, denote by $z^{i}=\left(z_{t}^{i}\right)_{t \geq 0}, i=1,2$, the two Brownian motions involved, and denote by $\xi \in(-1,1)$, the correlation between these two motions. Imperfect correlation between risky returns across countries, which is the second Obstfled's mild condition, 
is therefore set. Set $\mathbf{z}=\left(\begin{array}{c}z^{1} \\ z^{2}\end{array}\right)$. We can write it as $\mathbf{z}=\Xi \mathbf{y}$ with $\mathbf{y}=\left(\mathbf{y}_{t}\right)_{t \geq 0}:=$ $\left(\begin{array}{l}\left(y_{t}^{1}\right)_{t \geq 0} \\ \left(y_{t}^{2}\right)_{t \geq 0}\end{array}\right)$ two-dimensional Brownian motion and $\Xi=\left(\begin{array}{cc}1 & 0 \\ \xi & \sqrt{1-\xi^{2}}\end{array}\right)$. Let $r$ be the common riskless asset rate of return and $\alpha_{i o}$ the drift of the risky asset of country $i . \sigma_{i o}$ is the volatility of the risky asset of country $i$ after opening as already explained. In matrix form, we set $\boldsymbol{\alpha}=\left(\begin{array}{c}\alpha_{1 o} \\ \alpha_{2 o}\end{array}\right), \Sigma_{\mathbf{0}}=\left(\begin{array}{cc}\sigma_{1 o} & 0 \\ 0 & \sigma_{2 o}\end{array}\right), \mathbf{1}=\left(\begin{array}{l}1 \\ 1\end{array}\right) \in \mathbb{R}^{2}$.

Similar to the autarkic case, the budget equation for country $i$ at time $t$ is $W_{t}^{i}=$ $B_{t}^{i}+K_{t}^{i, 1}+K_{t}^{i, 2}$ and the dynamics of wealth accumulation for country $i$ follow

$$
d W_{t}^{i}=\left(r B_{t}^{i}+\left\langle\boldsymbol{\alpha}, \mathbf{K}_{t}^{i}\right\rangle-c_{t}^{i}\right) d t+\left\langle\mathbf{K}_{t}^{i}, \Sigma_{\mathbf{0}} \Xi d \mathbf{y}_{t}\right\rangle,
$$

with $\mathbf{M}:=\Sigma_{\mathbf{0}} \Xi=\left(\begin{array}{cc}\sigma_{1 o} & 0 \\ \xi \sigma_{2 o} & \sqrt{1-\xi^{2}} \sigma_{2 o}\end{array}\right)$. Define the capital share vector in total wealth as $\boldsymbol{\omega}_{t}^{i}=\left(\begin{array}{c}\omega_{t}^{i, 1} \\ \omega_{t}^{i, 2}\end{array}\right):=\mathbf{K}_{t}^{i} / W_{t}^{i}$, we have $B_{t}^{i} / W_{t}^{i}=1-\left\langle\boldsymbol{\omega}_{t}^{i}, \mathbf{1}\right\rangle$ and wealth accumulation equation becomes ${ }^{2}$

$$
d W_{t}^{i}=\left(r W_{t}^{i}+\left\langle\boldsymbol{\alpha}-r \mathbf{1}, \boldsymbol{\omega}_{t}\right\rangle W_{t}^{i}-c_{t}^{i}\right) d t+W_{t}^{i}\left\langle\boldsymbol{\omega}_{t}^{i}, \mathbf{M} d \mathbf{y}_{t}\right\rangle .
$$

As in the previous section, the country $i$ 's optimization problem is

$$
\max _{c_{t}^{i}, \omega_{t}^{i}} \mathbb{E} \int_{0}^{\infty} e^{-\rho_{i} t} \frac{\left(c_{t}^{i}\right)^{1-\gamma_{i}}}{1-\gamma_{i}} d t
$$

subject to the budget constraint (5).

Define $v_{i}\left(W^{i}\right)$ as the maximum feasible level of lifetime utility of country $i$, then country $i$ 's optimal consumption is $c_{t}^{i, *}=\left[v_{0}^{i}\left(1-\gamma_{i}\right)\right]^{-\frac{1}{\gamma_{i}}} W_{t}^{i, *}$, and the optimal share of risky asset vector is

$$
\boldsymbol{\omega}_{t}^{i, *} \equiv \frac{1}{\gamma_{i}} \Omega^{-1}(\boldsymbol{\alpha}-r \mathbf{1})=\frac{1}{\gamma_{i}}\left(\begin{array}{c}
\frac{\alpha_{10}-r}{\left(1-\xi^{2}\right) \sigma_{1 o}^{2}}+\frac{\xi\left(\alpha_{2 o-r}\right)}{\left(\xi^{2}-1\right) \sigma_{2 o} \sigma_{1 o}} \\
\frac{\xi\left(\alpha_{20}-r\right)}{\left(\xi^{2}-1\right) \sigma_{20} \sigma_{1 o}}+\frac{\alpha_{2 o}-r}{\left(1-\xi^{2}\right) \sigma_{2 o}^{2}}
\end{array}\right),
$$

with $\Omega:=\mathbf{M M}^{\mathbf{T}}=\left(\begin{array}{cc}\sigma_{1 o}^{2} & \sigma_{1 o} \sigma_{2 o} \xi \\ \sigma_{1 o} \sigma_{2 o} \xi & \sigma_{2 o}^{2}\end{array}\right)$. Thus, the wealth accumulation of country $i$ follows

$$
\frac{d W_{t}^{i}}{W_{t}}=\mu_{i} d t+\left\langle\boldsymbol{v}_{i}, d \mathbf{y}_{t}\right\rangle,
$$

where the constants $\mu_{i}$ and $\boldsymbol{v}_{i}=\left(v_{i}^{1}, v_{i}^{2}\right)$ are

$\left.\mu_{i}:=r+\frac{1}{\gamma_{i}}\left\langle\Omega^{-1}(\boldsymbol{\alpha}-r \mathbf{1}), \boldsymbol{\alpha}-r \mathbf{1}\right)\right\rangle-\left[v_{0}^{i}\left(1-\gamma_{i}\right)\right]^{-1 / \gamma_{i}}, \quad v_{i}:=\frac{1}{\gamma_{i}} \mathbf{M}^{-1}(\boldsymbol{\alpha}-r \mathbf{1})$.

\footnotetext{
${ }^{2}$ Here $\langle\cdot, \cdot\rangle$ denotes scalar product in $\mathbb{R}^{2}$, i.e.,

$$
\left\langle\mathbf{x}, \mathbf{x}^{\prime}\right\rangle=x_{1} x_{1}^{\prime}+x_{2} x_{2}^{\prime}, \quad \forall \mathbf{x}=\left(x_{1}, x_{2}\right), \forall \mathbf{x}^{\prime}=\left(x_{1}^{\prime}, x_{2}^{\prime}\right) .
$$
}


Therefore, the explicit form of optimal wealth for country $i$ in this open economy is $W_{t}^{i, *}=W_{0}^{i} \exp \left[\left(\mu_{i}-\frac{\left|\boldsymbol{v}_{i}\right|^{2}}{2}\right) t+\left\langle\boldsymbol{v}_{i}, \mathbf{y}_{t}\right\rangle\right]$, and the expected almost sure growth rate of country $i$ is

$$
g_{i o}:=\mu_{i}-\frac{1}{2}\left|\boldsymbol{v}_{i}\right|^{2}
$$

\section{The Gains and Losses from Financial Integration: the Case of Emerging Economies}

As explained before, we depart from Obstfeld (1994) by assuming that the volatility of country $i$ under autarky, $\sigma_{i a}$ may be different from the counterpart after opening, $\sigma_{i o}$. For simplicity, we keep all other parameters, such as $\gamma_{i}, \alpha_{i}$ and so on, unaltered after liberalization, though they may differ between the two countries.

Combining (4) and (7), it yields

$$
g_{i o}-g_{i a}=\frac{1}{2 \gamma_{i}}\left[\Gamma-\frac{\left(\alpha_{i}-r\right)^{2}}{\sigma_{i a}^{2}}\right] .
$$

It is easy to see that if $\sigma_{i a}=\sigma_{i o}$, then for both countries, $i=1,2$, we have

$$
g_{\text {io }}-g_{i a} \geq 0 \text {. }
$$

That is the case studied by Obstfeld (1994) and one can safely re-state his main result.

Proposition 2 Financial market liberalization always promotes both countries' long-run economic growth if there is no volatility change from an autarkic to an open economy.

However, as documented in the related empirical literature (see Bae et al. 2004, or Umutlu et al. 2010), at least some emerging markets did experience increases in volatility after financial market liberalization. More precisely, it has been documented that in some cases the volatility of the risky asset did rise. In other words, the equality $\sigma_{i a}=\sigma_{i o}$ may be violated in practice. We prove hereafter that if $\sigma_{i a}<\sigma_{i o}$, the unambiguous growth gain from financial integration pointed out by Obstfeld may be offset by this induced volatility increase (Stiglitz instability effect) under some appropriate conditions.

Actually, two different cases may appear when scrutinizing the set of emerging countries opening, say, to a single developed country.

1. The emerging market is sufficiently small compared to the developed world financial market, thus only the emerging economy's volatility changes and the other economy's volatility is unchanged.

2. The emerging economy is large enough, such as China and India. When these countries join the world financial market, it may affect the rest of the world as well. Thus, both the developing and emerging economy volatilities may change after financial market liberalization. 
However, to make our point, it is sufficient to study only the first case, which is indeed the best case for financial liberalization. In the second case, both the emerging economy and the originally developed economy may face a decrease in economic growth, provided the emerging economy is sufficiently large and, hence, influential (contagion effect).

Denote by $i=1$ the emerging economy, $i=2$ being the developed one. Suppose that $\sigma_{2 o}=\sigma_{2 a}=\sigma_{2}$ is unchanged. The following results can be demonstrated.

Proposition 3 Suppose that after financial market liberalization, there is no volatility change in country 2 , but the emerging economy, $i=1$, faces a volatility increase to some extent, such that,

$$
\sigma_{1 o}>\frac{\alpha_{1}-r}{y_{2}}
$$

with $y_{2}=\xi\left(\frac{\alpha_{2}-r}{\sigma_{2}}\right)+\sqrt{\left(1-\xi^{2}\right)\left[\left(\frac{\alpha_{1}-r}{\sigma_{1 a}}\right)^{2}-\left(\frac{\alpha_{2}-r}{\sigma_{2}}\right)^{2}\right]}$. Furthermore, if the two risky assets are negatively correlated, i.e. $\forall \xi \in(-1,0]$, the emerging economy experiences $g_{1 o}<g_{1 a}$ if and only if

$$
\frac{\alpha_{2}-r}{\sigma_{2}}<\sqrt{1-\xi^{2}}\left(\frac{\alpha_{1}-r}{\sigma_{1 a}}\right) .
$$

Proposition 4 Under the same assumptions as in the previous proposition, including (9), and provided the two risky assets are positively correlated, that is, $\forall \xi \in(0,1)$, then $g_{1 o}<g_{1 a}$ if and only if

$$
\frac{\alpha_{2}-r}{\sigma_{2}}<\frac{\alpha_{1}-r}{\sigma_{1 a}}
$$

The proofs are in the Appendix. A few remarks are in order here. First notice that Propositions 3 and 4 state conditions for growth detrimental financial liberalization under negative and positive correlation $\xi$ respectively. As it transpires, the case of negative correlation is more demanding, as fulfilling condition (10) is harder than fulfilling (11). In other words, Eq. 10 implies (11). Moreover, the larger the absolute value of $\xi$, the more demanding condition (10). This should not be surprising: the pure risk sharing effect works when risk diversification makes more sense, and this happens under negative correlation of the national risky assets' returns. Obviously, the "more negative" the correlation is, the harder for the Stiglitz instability effect to offset the Obstfeld risk sharing effect.

Second, in each Proposition, two conditions are indeed invoked. The first one, which is common to the two propositions, that is: $\sigma_{1 o}>\frac{\alpha_{1}-r}{y_{2}}$, gives the size of the instability effect induced by the liberalization, required to offset the Obstfeld effect. The second condition (Eq. 10 in Proposition 3 and (11) in Proposition 4) concerns the autarky phase. Recall that we define $\frac{\alpha_{i}-r}{\sigma_{i}}$ as relative-risk-averse-wealth volatility. Thus, the latter type of condition states that, for given developed world financial markets, if under autarky the emerging economy's wealth volatility is (at least) higher than the wealth volatility of the developed economy (the negative correlation case 
being the more demanding), there could be the case that after financial liberalization its long-run growth rate is lower than under autarky.

Summing up, as it transpires from the interpretation of the two types of conditions involved in the Propositions just above, our analysis allows to bridge the gap between the threshold literature à la Kose et al. (2011) and the instability literature inspired by Stiglitz: the outcomes of financial liberalization do not only depend on the fundamentals of the economies, that is on their characteristics before opening (as in the stream of literature led by Kose et al. (2011) but also on the size of the instability conveyed by liberalization. In our framework, we identify how big should be instability for the virtuous pure diversification effect to be dominated.

We now state some of the residual implications of the Propositions above. In particular, not surprisingly, it's shown that the developed country, for which there is no instability effect assumed, always benefits from financial integration.

Corollary 1 Suppose that after financial market liberalization, there is no volatility change in country 2, the developed economy, then

- country 2 always benefits from financial market liberalization of the emerging economy, that is, $g_{2 o}>g_{2 a}$ is always true;

- if condition (9) fails, or one of the two conditions (10) or (11) fail, then in the long run, both countries benefit from financial market liberalization.

\section{Conclusion}

In this note, we have extended Obstfled's international risk sharing model to account for the instability effect rightly pointed out by Stiglitz. We do so by relaxing one crucial assumption in the original framework, at a very reasonable algebraic cost. We have identified the conditions under which an emerging economy joining the international financial markets may experience a drop in growth. Interestingly, these conditions combine the typical threshold conditions one can find in the related literature, which concern the deep characteristics of the economies under autarky, and size conditions on the instability effects induced by liberalization (consistently with Stiglitz). While the non-robustness of Obstfeld's main conclusion to relaxing the above-mentioned assumption is not surprising, we believe that our framework has the virtue to highlight the key factors behind the success or failure cases of financial globalization at a minimal algebraic cost, ultimately allowing to give a unifying view of the (main) contradictory arguments on the benefits of financial globalization for developing and emerging countries.

Needless to say, our paper is limited by the fact that we do not model the instability effect as an endogenous mechanism but as an exogenous shock. Clearly part of the instability comes exogenously from external crises as outlined by Stiglitz. But it is also obvious that instability is favored by countries' own characteristics related to financial frictions and external vulnerability.

Acknowledgments We thank three anonymous referees for their careful reviewing. Geert Bekaert, Fausto Gozzi and Patrick Pintus are gratefully acknowledged for useful discussions. 


\section{Appendix: Proof of Proposition 3, 4 and their Corollary}

It is easy to check that $g_{1 o}<g_{1 a}$ if and only if

$$
\Gamma-\frac{\left(\alpha_{1}-r\right)^{2}}{\sigma_{1 a}^{2}}<0
$$

that is,

$$
\frac{\left(\alpha_{1}-r\right)^{2}}{\sigma_{1 o}^{2}}+\frac{\left(\alpha_{2}-r\right)^{2}}{\sigma_{2}^{2}}-\frac{2 \xi\left(\alpha_{1}-r\right)\left(\alpha_{2}-r\right)}{\sigma_{1 o} \sigma_{2}}<\left(1-\xi^{2}\right) \frac{\left(\alpha_{1}-r\right)^{2}}{\sigma_{1 a}^{2}} .
$$

To ease notations, define

$$
x=\frac{\alpha_{1}-r}{\sigma_{1 a}}, \quad y=\frac{\alpha_{1}-r}{\sigma_{1 o}}, \quad A=\frac{\alpha_{2}-r}{\sigma_{2}} .
$$

Then the above inequality can be rewritten into the form of a second degree polynomial:

$$
F(y)=y^{2}-2 \xi A y+A^{2}-\left(1-\xi^{2}\right) x^{2}<0,
$$

which has two roots:

$$
y_{1}=\xi A-\sqrt{\left(1-\xi^{2}\right)\left(x^{2}-A^{2}\right)}, \quad y_{2}=\xi A+\sqrt{\left(1-\xi^{2}\right)\left(x^{2}-A^{2}\right)} .
$$

Thus, $F(y)<0$ if and only if $y_{1}<y<y_{2}$ with $y_{1,2}$ real. Otherwise, it yields $g_{1 o}>g_{1 a}$.

The two roots $y_{1,2}$ may be complex or real, and if only real roots, there may be negative one(s).

Case I. Existence of complex roots.

Since $\xi \in(-1,1)$, the above roots, $y_{1,2}$, are real if and only if $x^{2}-$ $A^{2}>0$, that is,

$$
\frac{\alpha_{1}-r}{\sigma_{1 a}}>\frac{\alpha_{2}-r}{\sigma_{2}}
$$

given our assumption that $\alpha_{i}>r$ ( risky assets have higher expected returns than risk-free assets).

So the first conclusion is that if initially

$$
\frac{\alpha_{1}-r}{\sigma_{1 a}}<\frac{\alpha_{2}-r}{\sigma_{2}}
$$

we will always have $g_{1 a}<g_{1 o}$.

Case II. $y_{1,2}$ are real and $y_{1}<y_{2}<0$.

If both roots of Eq. 12 are negative, we must have $\xi<0$ and

$$
\sqrt{1-\xi^{2}}\left(\frac{\alpha_{1}-r}{\sigma_{1 a}}\right)<\left(\frac{\alpha_{2}-r}{\sigma_{2}}\right) \text {. }
$$

If so, for any $y>0$, we would have $F(y)>0$. Thus, we always have $g_{1 o}>g_{1 a}$.

Case III. $y_{1,2}$ are real and $y_{1}<0<y_{2}$. 
Then inequality (12) is true, that is $g_{1 o}<g_{1 a}$, if and only $0<y<y_{2}$, given assumption $\alpha_{i}>r$. In other words, $y_{1}<0<y_{2}$ if and only if

$$
A^{2}<\left(1-\xi^{2}\right) x^{2} \text {. }
$$

Case IV. $y_{1,2}$ are real and $0<y_{1}<y_{2}$.

In this case, we must have $\xi \in(0,1)$ (otherwise, $\left.y_{1}<0\right)$ and, $y_{1}>0$ if and only if

$$
\sqrt{1-\xi^{2}}\left(\frac{\alpha_{1}-r}{\sigma_{1 a}}\right)<\left(\frac{\alpha_{2}-r}{\sigma_{2}}\right) .
$$

Then, with the above condition under autarky, $g_{1 o}<g_{1 a}$ if and only if,

$$
y_{1}<y<y_{2} .
$$

However, it is straightforward to see that as long as $\sigma_{1 o}>\sigma_{1 a}$, we have

$$
y_{1}<y \text {. }
$$

Grouping the case III and IV depending on $\xi \in(-1,0]$ and $\xi \in(0,1)$, we have the following: (1) $\forall \xi \in(-1,0], g_{1 o}<g_{1 a}$ if and only if

$$
\frac{\alpha_{2}-r}{\sigma_{2}}<\sqrt{1-\xi^{2}}\left(\frac{\alpha_{1}-r}{\sigma_{1 a}}\right) \quad\left(<\frac{\alpha_{1}-r}{\sigma_{1 a}}\right) ;
$$

(2) $\forall \xi \in(0,1), g_{1 o}<g_{1 a}$ if and only if

$$
\frac{\alpha_{2}-r}{\sigma_{2}}<\frac{\alpha_{1}-r}{\sigma_{1 a}} .
$$

\section{References}

Bae K, Chan K, Ng A (2004) Investability and return volatility. J Financ Econ 71:239-263

Bekaert G, Harvey C (2000) Foreign speculators in emerging equity markets. J Financ 55:565-613

Bekaert G, Harvey C, Lundblad C (2005) Does financial liberalization spur growth? J Financ Econ 77(1):3-56

Bekaert G, Harvey C, Lundblad C (2006) Growth volatility and financial liberalization. J Int Money Financ 25:370-403

Boucekkine R, Pintus P (2012) History's a curse: leapfrogging, growth breaks and growth reversals under international borrowing without commitment. J Econ Growth 17:27-47

Boucekkine R, Fabbri G, Pintus P (2018) Short-run pain, long-run gain: the conditional welfare gains from international financial integration. Economic Theory 65:329-360

Eichengreen B (2001) Capital account liberalization: what do cross-country studies tell us. The World Bank Economic Review 15(3):341-365

Harvey C (1995) Predictable risk and returns in emerging markets. Studies Rev Financ Stud 8:773-816

Kitano S, Takaku K (2017) Capital controls and financial frictions in a small open economy. Open Econ Rev 28:761-793

Kose M, Prasad ES, Taylor AD (2011) Thresholds in the process of international financial integration. J Int Money Financ 30:147-179

Levine R (2001) International financial liberalization and economic growth. Rev Int Econ 9(4):688-702

Merton R (1971) Optimum consumption and portfolio rules in a continuous-time model. J Econ Theory 3:373-413

Moshirian F (2008) Globalisation, growth and institutions. J Bank Financ 32:472-479

Obstfeld M (1994) Risk-taking, global diversification and growth. Am Econ Rev 85:1310-1329

Prasad E, Rogoff K, Wei S, Kose M (2003) Effects of financial globalization on developing countries: some empirical evidence. Working paper 220, International Monetary Fund 
Ramey G, Ramey V (1995) Cross-Country Evidence on the link between volatility and growth. The Am Econ Rev 85(5):1138-1151

Stiglitz J (2000) Capital market liberalization, economic growth and instability. World Dev 26(6):10751086

Umutlu M, Akdeniz L, Altay-Salih A (2010) The degree of financial liberalization and aggregated stockreturn volatility in emerging markets. J Bank Financ 34:509-521 